\title{
Efficacy of Intralesional Methotrexate in the Treatment of Plantar Warts
}

Hamed Mohamed Abdo, Emad Mahmoud Elrewiny, Mohammed Shaban Elkholy*

Department of Dermatology, Venereology and Andrology, Faculty of Medicine, Al-Azhar University

*Corresponding author: Mohammed Shaban Elkholy, Mobile: (+20) 1068281377, Email: tantawy_wael@yahoo.com

\begin{abstract}
Background: Warts are tumors or growths caused by infection with Human Papilloma virus (HPV). Currently, over $170 \mathrm{HPV}$ types have been identified. They are common presenting disease in children and adolescents which spread by direct contact or autoinoculation.
\end{abstract}

Objective: The present work aimed to study the efficacy and safety of intralesional injection of methotrexate (MTX) for treatment of plantar warts and its possibility to be an alternative for the ordinary treatment.

Patients and methods: sixty Egyptian patients presented with plantar warts were enrolled into our study. The patients were recruited from the Dermatology Outpatient Clinic of Al-Azhar University Hospital in the period from January 2019 to June 2019. Patients were classified into; control group (30 patients) that were Injected by normal saline and study group (30 patients) that were injected by MTX.

Results: In intralesional MTX group, 2 patients (6.7\%) showed complete improvement, 8 patients $(26.7 \%)$ showed partial improvement and 20 patients $(66.7 \%)$ showed no improvement. In intralesional saline group, 3 patients (10\%) showed complete improvement, 4 patients $(13.3 \%)$ showed partial improvement and 23 patients (76.7) showed no improvement.

Conclusion: In this study, there was no statistically significant difference between the therapeutic responses to intralesional MTX injection and saline. Intralesional MTX injection was safe but less effective. No serious side effects were reported. Reported adverse events were local reactions in the form of swelling, pain and infection.

Keywords: Intralesional Methotrexate, Plantar Wartsj

\section{INTRODUCTION}

Warts are benign proliferations of skin and mucosa caused by the human papilloma virus (HPV). Currently, Over 170 HPV types have been identified. Certain HPV types tend to infect skin at particular anatomic sites, however, warts of any HPV type may occur at any site. Warts are transmitted by direct or indirect contact, and predisposing factors include disruption to the normal epithelial barrier ${ }^{(\mathbf{1})}$.

There are several modalities for treatment of warts including cryotherapy, electrocoagulation, topical salicylic acid, topical 5-fluorouracil, and laser surgery. All of these treatment options can be painful, time consuming, and/or expensive, and none is considered the gold standard ${ }^{(2)}$. Treatments for warts have also included intralesional injections of tuberculin purified protein derivative (PPD), measles, mumps, and rubella (MMR) vaccine and Candida albicans antigen (candidin). This treatment approach is known as intralesional immunotherapy as it is thought that these modalities activate the immune system to recognize the virus, leading to wart clearance ${ }^{(3)}$.

Methotrexate (MTX) is an anti-proliferative, anti-inflammatory and immuno-modulating agent, which was approved by the US food and drug administration (FDA) in $1971^{(4)}$.

\section{AIM OF THE WORK}

To study the efficacy and safety of intralesional injection of methotrexate for treatment of plantar warts and its possibility to be an alternative for the ordinary treatment.

\section{PATIENTS AND METHODS}

Sixty Egyptian patients presented with plantar warts were enrolled into our study. The patients were recruited from the Dermatology Outpatient Clinic of Al-Azhar University Hospital in the period from January 2019 to June 2019.

\section{Ethical approval and written informed consent:}

Informed written consents were obtained from all patients. The approval from the Research Ethical Committee of the Faculty of Medicine, Al-Azhar University Hospitals also was obtained.

Inclusions Criteria:

- Both males and females.

- Age: 18-60 years old.

- Single or multiple plantar warts. Exclusion criteria:

- Pregnancy and lactation.

- Age $<18$ or $>60$ years old.

- Immunosuppression or being under any kind of treatment causing absolute or relative immunosuppression.

- History of any bleeding/clotting disorder.

- Using of anticoagulants e.g warfarin or NSAIDs e.g. aspirin.

- Chronic systemic diseases such as chronic renal failure, hepatic insufficiency and cardiovascular disorders

- Concurrent use of systemic or topical treatments of warts. 


\section{Methods}

Each patient was subjected to:

Full history taking including:

- Age and sex,

○ Duration of the warts.

- Previous treatments received for the warts.

- Family history of same lesion.

- General examination for any associated skin diseases.

- Clinical evaluation of the patient to determine warts size $(<$ or $>1 \mathrm{~cm})$, number and distribution.

- Injection site was sterilized by alcohol $75 \%$.

$\bullet$ site 30 mintues before the injection.

- $\quad$ Study group: 30 patient were Injected by MTX $2 \mathrm{mg}$ per $\mathrm{ml}$ into the base of the warts using an insulin syringe till the lesion blanch. Injections were performed every week with a maximum of 6 sessions. A maximum of 5 warts were treated per patient in 1 session.

- Control group: 30 patien were Injected by normal saline into the base of the warts using an insulin syringe till the lesions blanch. Injections were performed every week.

- Clinical changes or adverse reactions were recorded.

- Evaluation of the response was carried out by:

- Clinical evaluation before and after the last session.

- Digital photography with camera (HUAWEI GRA-UL10/13 mega pixel, Y7L7N15A 09000120, made in China) before and 4 weeks after the last session.

Patients were considered cleared if all warts completely resolved; patients were considered partially responsive if some of the warts remained unchanged. The treatment was considered to have failed if no response was observed in any of the lesions.

\section{Statistical analysis:}

Data were analyzed using Statistical Program for Social Science (SPSS) version 15.0. Quantitative data were expressed as mean \pm standard deviation (SD). Qualitative data were expressed as frequency and percentage.

The following tests were done:

Independent-samples t-test of significance: was used when comparing between two means.

Chi-square test: was used when comparing between non-parametric data.

A one-way analysis of variance (ANOVA): when comparing between more than two means.

\section{Probability (P-value)}

- P-value $<0.05$ was considered significant.

- P-value < 0.001 was considered as highly significant.

- P-value > 0.05 was considered insignificant.

\section{RESULTS}

A total of 60 patients were enrolled into the study. Clinical data of the patients regarding age, sex, duration, size, number of the sessions, improvement and side effect, were displayed into table:

Table (5): Description of data in all studied patients

\begin{tabular}{|c|c|c|c|c|}
\hline ariables & & $\begin{array}{l}\text { Patients } \\
(\mathbf{N}=\mathbf{3 0})\end{array}$ & $\begin{array}{l}\text { Control } \\
(\mathbf{N}=\mathbf{3 0})\end{array}$ & P-value \\
\hline \multirow{2}{*}{ Age (years) } & Mean & 23.9 & 24.9 & \multirow{2}{*}{0.54} \\
\hline & $\pm \mathrm{SD}$ & 6.2 & 7.2 & \\
\hline \multirow{2}{*}{ Sex } & Male & $17(56.7 \%)$ & $18(60 \%)$ & \multirow{2}{*}{0.79} \\
\hline & Female & $13(43.3 \%)$ & $12(40 \%)$ & \\
\hline \multirow{2}{*}{ Duration (months) } & Mean & 9.5 & 5.7 & \multirow[b]{2}{*}{$0.033 * *$} \\
\hline & $\pm \mathrm{SD}$ & 8.6 & 3.8 & \\
\hline \multirow{2}{*}{ Number of warts } & Mean & 3.8 & 3.4 & \multirow{2}{*}{0.33} \\
\hline & $\pm \mathrm{SD}$ & 1.2 & 1.9 & \\
\hline \multirow{2}{*}{ Size of wart } & $>1 \mathrm{~cm}$ & $22(73.3 \%)$ & $12(40 \%)$ & \multirow{2}{*}{$0.009 * *$} \\
\hline & $<1 \mathrm{~cm}$ & $8(26.7 \%)$ & $18(60 \%)$ & \\
\hline \multirow{4}{*}{ Side effects } & No & $14(46.7 \%)$ & $14(46.7 \%)$ & \multirow{4}{*}{1.0} \\
\hline & Pain & $12(40 \%)$ & $12(20 \%)$ & \\
\hline & Infection & $2(6.7 \%)$ & $2(6.7 \%)$ & \\
\hline & Swelling & $2(6.7 \%)$ & $2(6.7 \%)$ & \\
\hline \multirow{3}{*}{ Improvement } & No improvement & $20(66.7 \%)$ & $23(76.7 \%)$ & \multirow[b]{3}{*}{0.41} \\
\hline & Partial improvement & $8(26.7 \%)$ & $4(13.3 \%)$ & \\
\hline & Complete improvement & $2(6.7 \%)$ & $3(10 \%)$ & \\
\hline
\end{tabular}

**: -value $<0.05$ is considered significant. Table (1) showed no statistical significant difference (p-value $>\mathbf{0 . 0 5})$ between studied groups as regard age, sex, number of warts, side effects and improvement. 
Moreover, Table (1) showed statistically significant difference (p-value $<\mathbf{0 . 0 5}$ ) between studied groups as regard duration of disease and size of warts.

Table (2): Correlation between improvement and age in patients group

\begin{tabular}{|c|c|c|c|c|c|}
\hline \multirow{2}{*}{\multicolumn{2}{|c|}{ Variables }} & \multicolumn{3}{|c|}{ Improvement } & \multirow[b]{2}{*}{ P-value } \\
\hline & & $\begin{array}{c}\text { No } \\
(\mathbf{n}=\mathbf{2 0})\end{array}$ & $\begin{array}{l}\text { Partial } \\
(n=8)\end{array}$ & $\begin{array}{c}\text { Complete } \\
(\mathrm{n}=2)\end{array}$ & \\
\hline \multirow{2}{*}{ Age (years) } & Mean & 23.8 & 23.6 & 25.0 & \multirow{2}{*}{0.96} \\
\hline & \pm SD & 6.4 & 6.3 & 7.1 & \\
\hline
\end{tabular}

Table (2) showed no statistical significant correlation (p-value $>\mathbf{0 . 0 5}$ ) between improvement and age in patients group.

Table (3): Correlation between improvement and duration of disease in patients group

\begin{tabular}{|c|c|c|c|c|c|}
\hline \multirow{2}{*}{ Variables } & & \multicolumn{3}{|c|}{ Improvement } & \multirow[b]{2}{*}{ P-value } \\
\hline & & $\begin{array}{c}\text { No } \\
(\mathbf{n}=\mathbf{2 0})\end{array}$ & $\begin{array}{c}\text { Partial } \\
(\mathbf{n}=8)\end{array}$ & $\begin{array}{c}\text { Complete } \\
(\mathbf{n}=2)\end{array}$ & \\
\hline \multirow{2}{*}{$\begin{array}{l}\text { Duration } \\
\text { (months) }\end{array}$} & Mean & 8.4 & 14.0 & 3.0 & \multirow{2}{*}{0.15} \\
\hline & \pm SD & 6.3 & 12.5 & 0.0 & \\
\hline
\end{tabular}

Table (3) showed no statistical significant correlation (p-value $>\mathbf{0 . 0 5}$ ) between improvement and duration of disease in patients group.

Table (4): Correlation between improvement and number of warts in patients group

\begin{tabular}{|c|c|c|c|c|c|}
\hline \multirow{2}{*}{\multicolumn{2}{|c|}{ Variables }} & \multicolumn{3}{|c|}{ Improvement } & \multirow[b]{2}{*}{ P-value } \\
\hline & & $\begin{array}{c}\text { No } \\
(n=20)\end{array}$ & $\begin{array}{c}\text { Partial } \\
(\mathbf{n}=8)\end{array}$ & $\begin{array}{c}\text { Complete } \\
(\mathrm{n}=2)\end{array}$ & \\
\hline \multirow{2}{*}{ No. of warts } & Mean & 3.9 & 4.1 & 4.5 & \multirow{2}{*}{0.61} \\
\hline & \pm SD & 1.1 & 0.8 & 0.7 & \\
\hline
\end{tabular}

Table (4) showed no statistical significant correlation ( $\mathbf{p}$-value $\mathbf{>} \mathbf{0 . 0 5}$ ) between improvement and number of warts in patients group.

Table (5): Correlation between improvement and sex in patients group

\begin{tabular}{|c|c|c|c|c|c|}
\hline \multirow{2}{*}{\multicolumn{2}{|c|}{ Variables }} & \multicolumn{3}{|c|}{ Improvement } & \multirow[b]{2}{*}{ P-value } \\
\hline & & $\begin{array}{c}\text { No } \\
(n=20)\end{array}$ & $\begin{array}{l}\text { Partial } \\
(\mathrm{n}=8)\end{array}$ & $\begin{array}{c}\text { Complete } \\
(\mathrm{n}=2)\end{array}$ & \\
\hline \multirow{2}{*}{ Sex } & Male & $12(60 \%)$ & $4(50 \%)$ & $1(50 \%)$ & \multirow{2}{*}{0.87} \\
\hline & Female & $8(40 \%)$ & $4(50 \%)$ & $1(50 \%)$ & \\
\hline
\end{tabular}

Table (5) showed no statistical significant correlation (p-value $>\mathbf{0 . 0 5}$ ) between improvement and sex in patients group. In non-improved patients, there were 12 males (60\%) and 8 females (40\%). In partially improved patients, there were 4 males $(50 \%)$ and 4 females (50\%). While, in completely improved patients, there were 1 male $(50 \%)$ and 1 female $(50 \%)$.

Table (6): Correlation between improvement and size of wart in patients group.

\begin{tabular}{|c|c|c|c|c|c|}
\hline \multirow{2}{*}{\multicolumn{2}{|c|}{ Variables }} & \multicolumn{3}{|c|}{ Improvement } & \multirow[b]{2}{*}{ P-value } \\
\hline & & $\begin{array}{c}\text { No } \\
(n=20)\end{array}$ & $\begin{array}{l}\text { Partial } \\
(n=8)\end{array}$ & $\begin{array}{c}\text { Complete } \\
(\mathrm{n}=2)\end{array}$ & \\
\hline \multirow[t]{2}{*}{ size } & $>1 \mathrm{~cm}$ & $19(95 \%)$ & $3(37.5 \%)$ & $1(50 \%)$ & \multirow{2}{*}{0.003 ** } \\
\hline & $<1 \mathrm{~cm}$ & $1(5 \%)$ & $5(62.5 \%)$ & $1(50 \%)$ & \\
\hline
\end{tabular}

$*$ : p-value $<0.05$ is considered significant. 
Table (6) showed statistically significant correlation (p-value $<\mathbf{0 . 0 5}$ ) between improvement and size of wart in patients group.

Clinical photos of selected cases are demonstrated below in figures (1- 5)

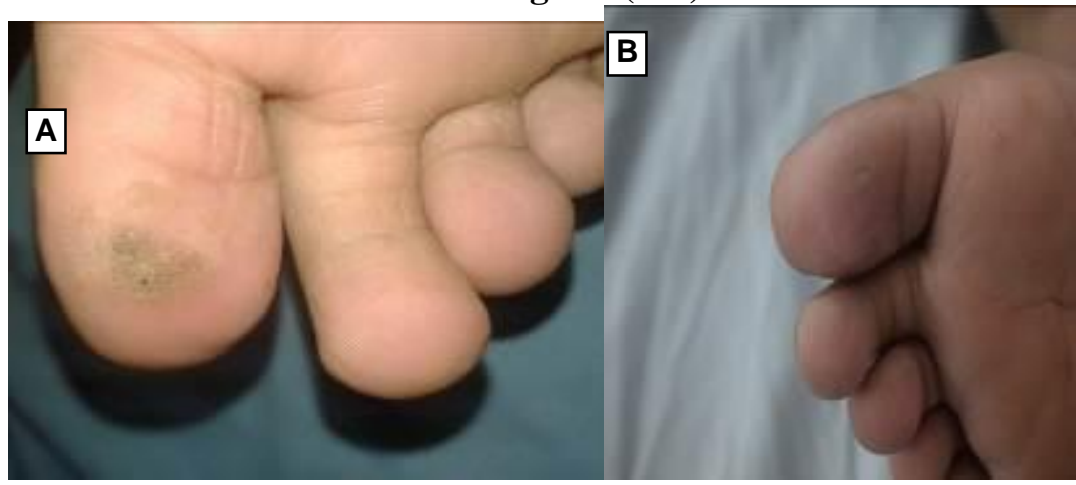

Figure (1): Male patient, 18 years old, with a single mosaic plantar wart more than $1 \mathrm{~cm}$ affecting the big toe of 1 year duration showed complete response after 6 sessions of MTX injection. (A) Before treatment. (B) After treatment.

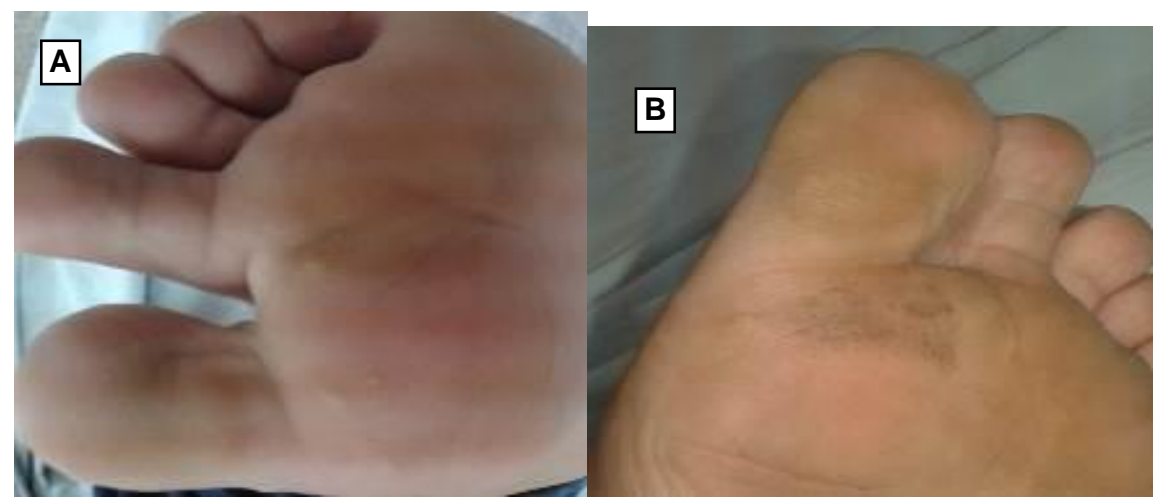

Figure (2): Female patient, 19 years old, with multiple plantar warts of 3 months duration showed complete response after 6 sessions of MTX injection. (A) Before treatment. (B) After treatment.
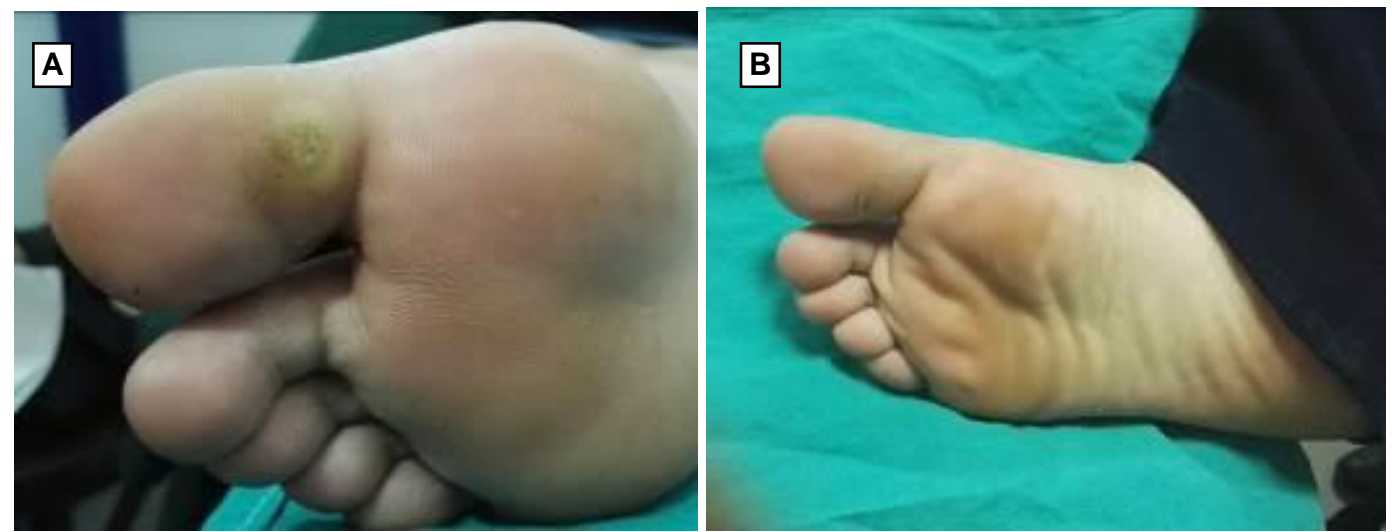

Figure (3): Female patient, 22 years old, with a single planter wart of 10 months duration showed complete response 6 sessions of saline injection. (A) Before treatment. (B) After treatment.

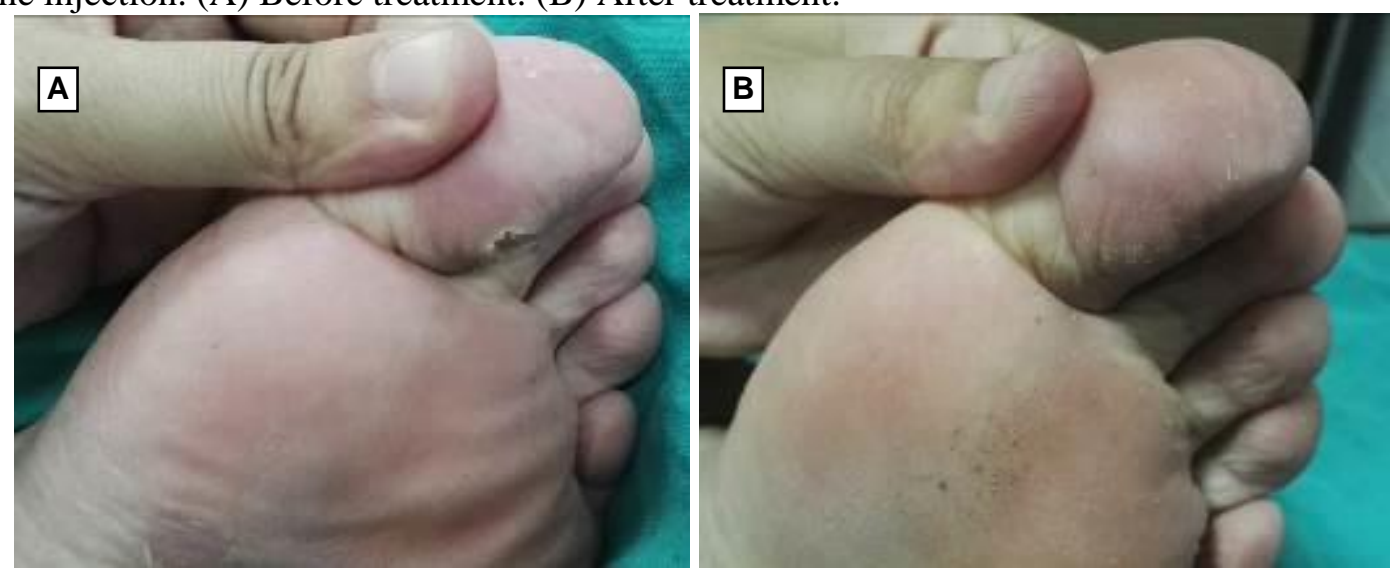


Figure (4): Female patient, 19 years old, with a single planter wart of 1 year duration showed partial response after 6 session of MTX injection. (A) Before treatment. (B) After treatment.
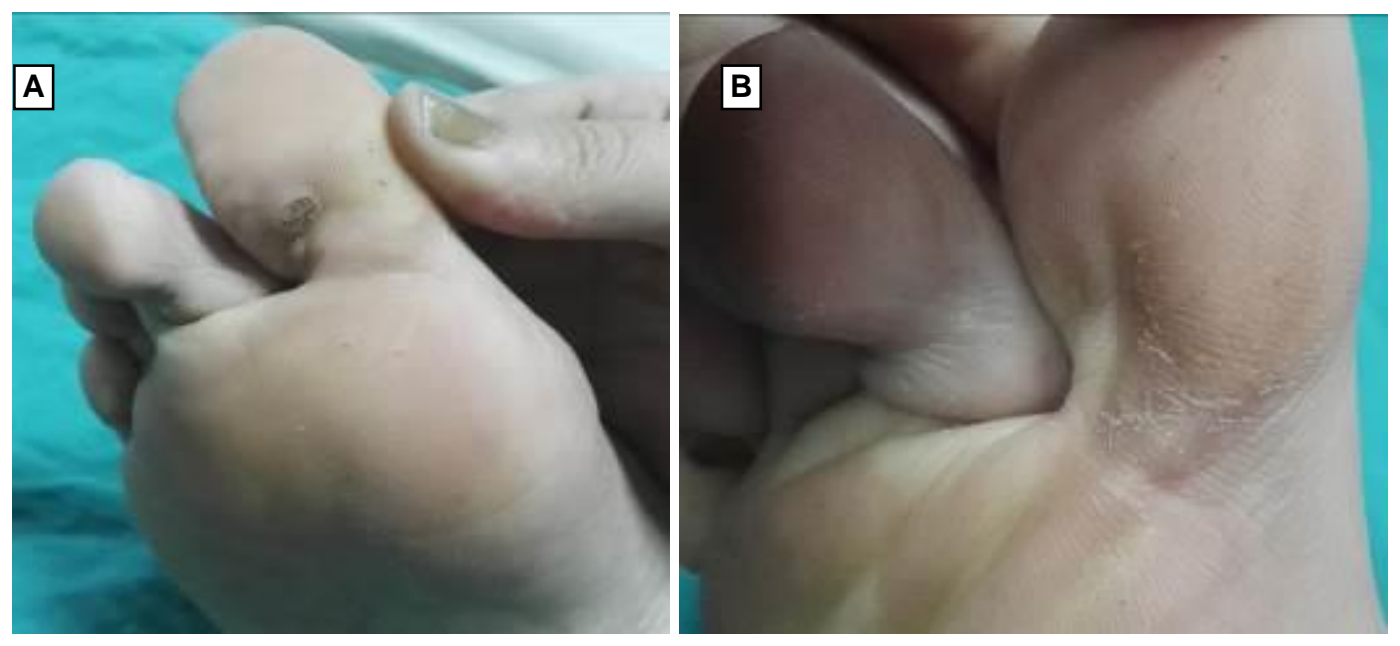

Figure (5): Female patient, 25 years old, with a single planter wart of 5 months duration showed complete response after 6 sessions of saline injection. (A) Before treatment. (B) After treatment.

\section{DISCUSSION}

MTX is an anti-proliferative, anti-inflammatory and immuno-modulating agent which was approved by the US food and drug administration (FDA) in $1971^{(4)}$. MTX is appropriate for rapidly growing tumors since it inhibits DNA synthesis in actively dividing cells. MTX is a folic acid analogue that binds to the dihydrofolate reductase, blocking the formation of tetrahydrofolate and preventing the synthesis of the purine nucleotide thymidine ${ }^{(5)}$.

To the best of our knowledge there is no reported use of intralesional MTX in the treatment of viral warts, except one report by Al-Khafaji et al. (6) who compared between intralesional MTX and electrocautery in treatment of common warts. Al-Khafaji et al. (6) performed their study on 42 patients (12 males and 30 females) 12-32 years old (mean age, 22.2 years) clinically diagnosed as having common warts on at least two symmetrical limbs (upper or lower) and counted to form two groups of right sided and left sided warts. Each side of patient was treated with either MTX intralesionally or electrocautery. The mean number of warts was 4.52 on upper limbs and 3.9 on lower limbs. A $6.78 \%$ of these warts which was treated with intralesional MTX were cleared compared to $22.6 \%$ for electrotherapy. They found that MTX have clearance rate less than electrocautery in treating common warts.

Our study included 60 patients with plantar warts (aged 18- 60 years with a mean of 23.9 years old). 30 patients were injected with MTX (17 males and 13 females) in comparison with 30 patients that were injected by normal saline (18 males and 12 females) as a placebo. The mean number of warts was 3.8 for MTX group and 3.4 for control group. In MTX group, 2 patients $(6.7 \%)$ showed complete improvement, 8 patients (26.7\%) showed partial improvement and 20 patients $(66.7 \%)$ showed no improvement. In agreement with Al-Khafaji et al. (6), our study discloses that intralesional MTX was less effective in treating planter warts.

The use of intralesional MTX in keratoacanthoma has been reported in more than 50 subjects aged between 53 and 90 years. In these patients, MTX was in general use with an average of 2.1 injections with an average cumulative dose of $38.2 \mathrm{mg}$. Intralesional MTX injections were spaced 22 days. A complete response was achieved in more than $80 \%$ of the treated subjects. In general, the treatment was well tolerated. The authors confirmed that intralesional MTX could be considered an effective and safe treatment of keratoacanthoma with minimal side effects. To apply these findings on wart treatment, large-scale studies on different clinical varieties of wart and using different dose regimens should be performed. Also, why intralesional MTX is an effective treatment in keratoacanthoma and not in wart needs to be explored ${ }^{(7,8)}$.

Several studies were performed using intralesional immune therapy, cytotoxic drugs and anti-proliferative as 5-fluorouracil (5-FU) and bleomycin in treating plantar warts. Intralesional 5-FU was used by Srivastava $\boldsymbol{e t}$ al. (9) for treating warts. They performed their study on 50 patients with 1-5 palmo-plantar warts, whose age ranged from 15 to 50 years old. Patients were categorized into two groups of 25 
each. Group A was treated with intralesional 5FU and Group B was treated with normal saline (placebo). 5-FU (4 cm3; $50 \mathrm{mg} / \mathrm{mL})$ combined with lidocaine $(1 \mathrm{~cm} 3 ; 20 \mathrm{mg} / \mathrm{mL})$ and epinephrine $(0.0125 \mathrm{mg} / \mathrm{mL})$ solution was injected into the base of the wart using a Mantoux needle. Each lesion was injected every week for up to a maximum of 4 weeks. The cure rate was $95.38 \%$ denoting that 5 -FU is safe and effective in treating palmoplantar warts. Yazdanfar et al. (10) used intralesional 5-FU in the same dosing schedule to treat common warts. Complete response was observed in $64.7 \%$ of the warts treated with 5-FU group compared to $35.3 \%$ in the warts treated with placebo $(\mathrm{p}<$ 0.05). Systemic reaction or treatment-related adverse events and recurrence rate did not differ significantly between the two groups. Intralesional 5-FU was a safe and effective approach for common warts with high success rate.

Intralesional bleomycin was used by Soni et al. (11) for treating warts. Soni et al., performed their study on 50 patients with multiple palmoplantar and periungual warts. They were categorized into groups A (no. 25, treated with intralesional bleomycin, $1 \mathrm{mg} / \mathrm{mL}$ solution) and B (no. 25, treated with normal saline as placebo). Injection was done fortnightly for maximum up to two injections. The cure rate in group $\mathrm{A}$ and $\mathrm{B}$ patients was $96.47 \%$ and $11.11 \%$ respectively. They concluded that the intralesional injection of bleomycin was effective, safe, and non-toxic in periungual and palmo-plantar warts.

Comparing the result of our study with the previously mentioned results, we can come to a conclusion that MTX is less effective in treating plantar warts compared to bleomycin and 5-FU. The results of the present work are limited by the low number of cases included in the study. Further studies are required to ascertain the efficacy of MTX injection in treating plantar warts.

\section{CONCLUSION}

In this study, there was no statistically significant difference between the therapeutic responses to intralesional MTX injection and saline. Intralesional MTX injection was safe but less effective. No serious side effects were reported. Reported adverse events were local reactions in the form of swelling, pain and infection.

\section{RECOMMENDATIONS}

Large-scale studies on different clinical varieties of wart and using different intralesional MTX dose regimens are recommended.

\section{REFERENCES}

1. Ghittoni R, Accardi RC, Hiocca S et al. (2015): Role of humanpapillomavi-ruses in carcinogenesis. E Canc Med Sci., 9: 526.

2. Kimura U, Takeuchi K, Kinoshita A et al. (2014): Long-pulsed 1064-nm neodymium: yttriumaluminumgarnet laser treatment for refractory warts on hands and feet. J Dermatol., 41: 252-257.

3. Shaheen MA, Salem SA, Fouad DA et al. (2015): Intralesional tuberculin (PPD) versus measles, mumps, rubella (MMR) vaccine in treatment of multiple warts: a comparative clinical and immunological study. Dermatol Ther., 28 (4): 194-200.

4. Qureshi MY, Memon ZH, Bibi I (2017): Methotrexateoutcome in the treatment of plaque psoriasis. Professional Med J., 24 (4): 607-611.

5. Cipriani P, Ruscitti P, Carubbi F et al. (2014). Methotrexate: an old new drug in autoimmune disease. Exper Rev ClinImmunol., 10: 1519-1530.

6. Al-Khafaji BA, Al-Kelaby HN, Alkhafaji KA (2010): Evaluation of Intralesional Methotrexate in Comparison with Electrocutary in Treatment of Common Warts. Medical Journal of Babylon, 7: 379382.

7. Della Valle V, Milani M (2018): Efficacy and Safety of Intralesional Methotrexate in the Treatment of a Large Keratoacanthoma of the Dorsal Hand in a 99-Year-Old Woman.Case Rep Dermatol., 10: 247-250.

8. Annest NM, VanBeek MJ, Arpey CJ et al. (2007): Intralesional methotrexate treatment for keratoacanthoma tumors: a retrospective study and review of the literature. J Am Acad Dermatol., 56 (6): 989-93.

9. Srivastava A, Ghiya BC, Soni P et al. (2016): Efficacy of Intralesional 5-Fluorouracil in Treatment of PalmoPlantar Warts. Int J Med Res., 2 (3): 60-63.

10. Yazdanfar A, Farshchian M, Fereydoonnejad M et al. (2008): Treatment of common warts with an intralesional mixture of 5-fluorouracil, lidocaine, and epinephrine: a prospective placebo-controlled, doubleblind randomized trial. Dermatol Surg., 34 (5): 656-9.

11.Soni P, Khandelwal K, Aara $\mathbf{N}$ et al. (2011): Efficacy of Intralesional Bleomycin in Palmo-plantar and Periungual Warts. J Cutan Aesthet Surg., 4 (3): 188-91. 